\title{
Experimental and numerical investigation of a stagnation pulverised coal flame
}

\author{
Michele Vascellari ${ }^{\mathrm{c}, *}$, Danny Messig ${ }^{\mathrm{a}}$, Arne Scholtissek ${ }^{\mathrm{a}}$, \\ Christian Hasse $^{a}$, Meng Xia ${ }^{b}$, Benoît Fiorina ${ }^{b}$, Nasser Darabiha ${ }^{b}$
}

\begin{abstract}
A multi-stream Flamelet Progress Variable (FPV) model, specifically developed for coal combustion, is proposed. The model accounts for the different fuel streams associated with the volatile and char burnout products. The applicability of the new FPV model is investigated in a laminar stagnation pulverized coal flame. The flame considered is a premixed mixture of $\mathrm{CH}_{4}, \mathrm{O}_{2}$ and $\mathrm{N}_{2}$, carrying pulverized coal particles, stabilized in an impinging wall. Spontaneous emissions of $\mathrm{OH}^{*}, \mathrm{CH}^{*}$ and $\mathrm{C}_{2}^{*}$ are measured to identify the flame. The 1D numerical simulations of the experimental conditions are able to reproduce the main features of the flame. The applicability of the multi-stream FPV model to coal combustion is further evaluated with the $a$ posteriori analysis of the FPV results, comparing the results with a reference model, where the species are fully transported and the chemistry directly evaluated. Then, with the budget analysis, the influence of the control variables used to build the look-up table is assessed by examining the conditional contributions to the overall transport terms of scalar quantities (e.g. species, temperature). The results of both analyses show that the proposed multi-stream FPV model can accurately predict the main features of coal combustion, with only minor issues related to the manifold used to build the look-up table.
\end{abstract}

\section{Introduction}

Since the pioneering work from Kurose and Makino [1], LESs have become more popular in the recent years for simulating Pulverized Coal Combustion (PCC) [2-7]. Turbulent combustion models based on tabulated chemistry methods are widely 
used for reactive LESs to include detailed kinetics in CFD simulations [8]. The thermo-chemical state of the reacting flow is defined by a limited number of representative control variables, and it is usually pre-computed using canonical reference flamelets. Flamelet-based LES's of PCC burners have been recently carried out [9-14]. However, because of the intense mass and heat exchange between the solid and the gas phase during the thermo-chemical conversion of the coal particles, extension of the tabulation methods for coal combustion is not straightforward [15]. Further, additional control variables are required to monitor the composition of gases released during pyrolysis and char conversion.

As demonstrated for turbulent gas flame, the development and validation of new combustion models should be performed systematically. The counter- and stagnation flows are widely used canonical configurations. With such setups, we can accurately evaluate flamelet models in a welldefined geometry under controlled conditions. In particular, the absence of turbulent fluctuations, allows to carefully evaluate the new modeling approach, without any potential bias by turbulence. This approach was used by Messig et al. [15] for validating the Flamelet Progress Variable (FPV) approach [16] in strained coal flames in a counter-flow burner, showing that interphase heat transfer plays a fundamental role in coal combustion and the enthalpy has to be directly included in the look-up tables as a control variable. However, only the volatile products were considered as a fuel stream released in the gas phase, ignoring the influence of char conversion on the combustion process. This assumption is generally valid for small lab-scale flames, where only low conversion of char can be achieved because of low residence times and slow conversion rates. However, char conversion cannot be neglected in large-scale furnaces, where almost complete conversion is aimed for. More work is therefore necessary to assess the influence of char conversion on the tabulated chemistry.

In this work, the FPV model is further extended to include the char burnout products as an additional fuel stream. The new multi-stream FPV model is tested in the stagnation coal/ $/ \mathrm{CH}_{4} / \mathrm{O}_{2} / \mathrm{N}_{2}$ strain burner, previously studied by Xia et al. [17], for conditions which maximize the char conversion. Due to its well-defined boundary conditions and laminar flow field this setup is well suited for model assessment. The 1D numerical results are first validated against the measured signals of the $\mathrm{OH}^{*}$, $\mathrm{CH}^{*}$ and $\mathrm{C}_{2}^{*}$ chemiluminescence. The a posteriori analysis of the FPV results is carried out using the results obtained from fully transporting the chemical species and directly solving the chemistry as a reference solution. Then, the influence of the control variables used to parameterize the look-up table is examined by means of a budget analysis. The influence of the individual control variables can be assessed by evaluating the conditional contribu-
Table 1

Proximate and ultimate analysis of Heizprofi (HP) lignite.

\begin{tabular}{lclc}
\hline \multicolumn{2}{l}{ Proximate an. $\left(\mathrm{wt}^{2} \%\right)$} & \multicolumn{2}{l}{ Ultimate an. $(\mathrm{wt} \%)$} \\
\hline $\begin{array}{l}\text { Volatile } \\
\text { matter }\end{array}$ & 50.6 & $\mathrm{C}$ & 69.0 \\
$\begin{array}{l}\text { Fixed } \\
\text { carbon }\end{array}$ & 45.1 & $\mathrm{H}$ & 5.0 \\
Moisture & 19 & $\mathrm{O}$ & 24.7 \\
Ash & 4.3 & $\mathrm{~N}$ & 0.8 \\
& & $\mathrm{~S}$ & 0.5 \\
\hline
\end{tabular}

tions of each control variable to the overall transport terms.

\section{Experimental setup}

The coal/ $/ \mathrm{CH}_{4} / \mathrm{O}_{2} / \mathrm{N}_{2}$ stagnation strained flame setup described in [17] is illustrated in Fig. 1. Coal particles with a mean Sauter diameter of $15 \mu \mathrm{m}$ are introduced at ambient pressure from the $10 \mathrm{~mm}$ convergent nozzle. Particles are transported in a mixture of $\mathrm{N}_{2}, \mathrm{O}_{2}$ and $\mathrm{CH}_{4}$. The flame is stabilized with an horizontal metallic brass wall positioned at a distance $L=20 \mathrm{~mm}$ from the nozzle. The configuration yields a symmetric flow field with respect to the axis $x$. The burner is fed with a predried Heizprofi (HP) lignite coal, whose ultimate and proximate analyses are reported in Table 1 . The mass fraction of coal with respect to the gas stream is 0.066 . The inlet velocity $v_{\text {in }}=2.6 \mathrm{~m} / \mathrm{s}$, which corresponds to a strain rate $k=v_{\text {in }} / L=1301 / \mathrm{s}$. Two different operating conditions are experimentally investigated in this work, named Flames 1 and 2. In Flame 1, the $\mathrm{O}_{2}$ volume fraction is $30 \%$ and the equivalence ratio between $\mathrm{CH}_{4}$ and the oxidizer $\Phi$ is 0.563 . In Flame $2, \mathrm{O}_{2}$ is $28 \%$ and $\Phi$ is 0.64 . The spontaneous emissions of chemiluminescent $\mathrm{OH}^{*}$, $\mathrm{CH}^{*}$ and $\mathrm{C}_{2}^{*}$ are measured by a CCD camera with different spectral band pass filters [17]. These data are used to validate the numerical simulations.

\section{Numerical models}

The strained stagnation flow flame can be described using a set of one-dimensional transport equations obtained by a similarity transformation [18]. The thermo-chemical state of the flow is modeled using two different approaches. The Full Transport and Chemistry (FTC) model [15] solves the balance equations of the chemical species and directly evaluates the chemical reaction rates. The Flamelet Progress Variable (FPV) model [16] uses at least the mixture fraction and the progress variable as representative control variables to fully describe the flow thermo-chemical state, which is normally pre-computed and stored in flamelet look-up tables. Thus, only a limited set of scalars is 


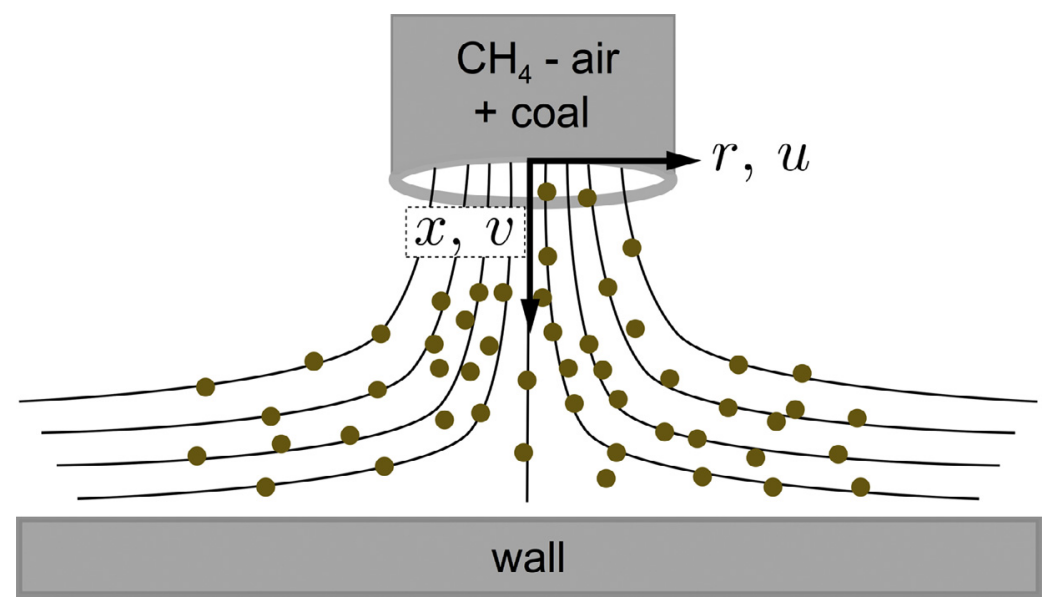

Fig. 1. Schematic view of the stagnation flame burner.

transported instead of the full set of temperature and species equations.

\subsection{Full transport and chemistry (FTC) model}

The transport equations for the mass, radial momentum, energy and species in the gas phase are solved assuming $\mathrm{Le}=1$. The validity of this assumption was tested against a reference solution with detailed multi-species diffusivity showing a limited impact, mainly related to the fact that $\mathrm{C}_{6} \mathrm{H}_{6}$ released is quickly consumed by the oxidation reactions, limiting the impact of the Le = 1 assumption. They contain additional terms to account for the interphase exchanges with the dispersed solid particles $[15,17]$ :

$$
\begin{aligned}
2 \rho U+\frac{\partial \rho v}{\partial x}= & \dot{M}_{s} \\
\rho U^{2}+\rho v \frac{\partial U}{\partial x}= & \frac{\partial}{\partial x}\left(\mu \frac{\partial U}{\partial x}\right)+J \\
& +n_{s} \frac{F_{r}}{r}+\dot{M}_{s}\left(U_{s}-U\right)
\end{aligned}
$$

$\rho c_{p} v \frac{\partial T}{\partial x}=\frac{\partial}{\partial x}\left(\lambda \frac{\partial T}{\partial x}\right)-\sum_{k=1}^{N_{s}} \rho Y_{k} V_{k} c_{p, k} \frac{\partial T}{\partial x}+n_{s} \dot{q}$

$-\sum_{k=1}^{N_{s}} h_{k} \dot{\omega}_{k}$

$+\dot{M}_{s} \sum_{k=1}^{N_{s}} Y_{k, s}\left[h_{k}\left(T_{p}\right)-h_{k}\left(T_{g}\right)\right]$

$$
\rho_{g} v_{g} \frac{\partial Y_{k}}{\partial x}=-\frac{\partial}{\partial x}\left(\rho_{g} Y_{k} V_{k x}\right)+\dot{\omega}_{k}
$$$$
+\dot{M}_{s}\left(Y_{k, s}-Y_{k}\right)
$$

where $u$ and $v$ are the radial and axial velocity components as illustrated in Fig. 1, and $U=u / r$ is the scaled radial velocity. The subscript $s$ denotes the particle quantities. $n_{s}$ defines the particle number volume density. $\dot{M}_{s}=n_{s} \dot{m}_{s}$ is the overall mass source term from the solid particles to the gas phase per volume. The single particle source term $\dot{m}_{s}=$ $\dot{m}_{v}+\dot{m}_{c}$ is the sum of the volatiles $\dot{m}_{v}$ and char burnout $\dot{m}_{c}$ contributions. The volatile and char oxidation products are released in the gas with mass fractions $Y_{k, s}=\left(\dot{m}_{v} Y_{k, v}+\dot{m}_{c} Y_{k, p}\right) / \dot{m}_{s}$. The models for the coal conversion source terms are described in Section 4.

In addition, the conservation equations for mass, momentum, energy and number density for the disperse coal particles are solved:

$v_{s} \frac{\partial m_{s}}{\partial x}=-\dot{m}_{s}$

$m_{s} U_{s}^{2}+m_{s} v_{s} \frac{\partial U_{s}}{\partial x}=-\frac{F_{r}}{r}$

$m_{s} v_{s} \frac{\partial v_{s}}{\partial x}=-F_{x}$

$m_{s} v_{s} c_{p, s} \frac{\partial T_{s}}{\partial x}=-\dot{q}-\dot{m}_{s} \Delta h_{s}\left(T_{p}\right)$

$2 n_{s} U_{s}+\frac{\partial n_{s} v_{s}}{\partial x}=0$.

Interphase terms include the drag forces $F_{x}$ and $F_{r}$, defined by Stokes law, the convective and radiative heat fluxes $\dot{q}$, and the chemical heat $\Delta h_{s}\left(T_{p}\right)[15,17]$. Radiative heat fluxes are modeled as described by Xia et al. [17].

\subsection{Flamelet Progress Variable (FPV) model}

In the FPV model the thermo-chemical state (temperature, species, etc.) is parameterized and 
expressed as a function of few control variables [16]. Thereby, the thermochemical state is represented by a low dimensional manifold, which can be pre-computed and stored in flamelet look-up tables.

In order to account for the different products released in the gas phase during coal thermochemical conversion, two mixture fractions are defined: one for the volatiles $Z_{v}$ and one for char burnout products $Z_{p}$. The general definition is:

$Z_{i}=\frac{m_{i}}{m_{g}+m_{v}+m_{c}}$,

where $i$ can be referred to volatiles $v$ or char products $p . m_{g}$ is the mass of the $\mathrm{CH}_{4} /$ oxidizer mixture. $m_{v}$ and $m_{p}$ are the mass of volatiles and char burnout products, respectively. The mass of char products $m_{p}=m_{c}(1+\alpha)$ is proportional to the mass of char converted $m_{c}$, where $\alpha$ is the stoichiometric oxidizer-to-char mass fraction [11]. The composition of $Z_{v}$ is defined according to the devolatilization model (see Section 4), while the composition of $Z_{p}$ is obtained from the products of the char partial oxidation [11]:

$C_{s}+\frac{1}{2}\left(\mathrm{O}_{2}+\sum_{j} \frac{X_{j}}{X_{\mathrm{O}_{2}}} S P_{j}\right) \longrightarrow \mathrm{CO}+\frac{1}{2} \sum_{j} \frac{X_{j}}{X_{\mathrm{O}_{2}}} S P_{j}$,

where $S P_{j}$ are the species in the oxidizer not reacting with the char.

For a similar problem with two fuel streams, a transformation for the control parameters was suggested in [19]. Extending the idea to coal combustion, the following parameters are defined: the overall fuel mixture fraction $Z=Z_{v}+Z_{p}$ and the fraction of volatiles in the fuel $Y=Z_{v} /\left(Z_{v}+Z_{p}\right)$. Both parameters are defined in a range from 0 to 1 . The progress variable is defined as a linear combination of the species mass fractions $Y_{C}=\sum_{k} \alpha_{k} Y_{k}$. The total enthalpy of the gas phase $h$ is defined as an additional control variable, which accounts for the heat transfer between the gas phase and the disperse coal particles and the wall. Both $Y_{C}$ and $h$ are normalized using the minimum and maximum values for each $Z$ and $Y$.

The non-adiabatic flamelet look-up table is generated using 1D premixed flamelets, solved in physical space. In fact, tables based on diffusion flamelets, which showed better results in the counter-flow setup [15], cannot correctly describe the pilot $\mathrm{CH}_{4}$ flame. In its original formulation the FPV model was always coupled to non-premixed look-up tables. However, premix tables were also recently used in the FPV context [15,20,21]. The FPV model is formally equivalent to the FPI [22] and FGM [23] approaches, initially developed for premixed flamelets. In fact, the definition of the FPV model in this work is more related to the way the reacting flow is parameterized, and not underlying type of manifold.
Solutions are then mapped from the physical axial coordinate $x$ to the progress variable space $Y_{C}$. Enthalpy is included in the table using nonadiabatic burner-stabilized premixed flamelets for which the total enthalpy is reduced at the isothermal nozzle. Different enthalpy levels are obtained using different inlet velocities. The methodology used was presented by Fiorina et al. [24].

In the FPV model, the flow field is described by Eqs. (1) and (2). The disperse solid phase is modeled as described in Section 3.1. Additional transport equations are solved for the volatile and the char products mixture fraction, respectively, for the progress variable and for the enthalpy:

$$
\begin{aligned}
\rho v \frac{\partial Z_{i}}{\partial x}= & \frac{\partial}{\partial x}\left(\rho D_{Z} \frac{\partial Z_{i}}{\partial x}\right)+\dot{M}_{i}-\dot{M}_{s} Z_{i} \\
\rho v \frac{\partial Y_{C}}{\partial x}= & \frac{\partial}{\partial x}\left(\rho D \frac{\partial Y_{C}}{\partial x}\right)+\sum_{k=1}^{N_{s}} \alpha_{k} \dot{\omega}_{k} \\
& +\dot{M}_{s} \sum_{k=1}^{N_{s}} \alpha_{k}\left(Y_{k, s}-Y_{k}\right) \\
\rho v \frac{\partial h}{\partial x}= & \frac{\partial}{\partial x}\left(k \frac{\partial T}{\partial x}\right)-\sum_{k=1}^{N_{s}} \frac{\partial}{\partial x}\left(\rho Y_{k} V_{k} h_{k}\right)+n_{p} \dot{q} \\
& -\dot{M}_{s} h+\sum_{k=1}^{N_{s}} \dot{M}_{s} Y_{k, s} h_{k}\left(T_{p}\right),
\end{aligned}
$$

where $\dot{M}_{v}=n_{p} \dot{m}_{v}$ and $\dot{M}_{c}=n_{p} \dot{m}_{c}$.

\subsection{Budget analysis}

The application of premixed flamelet manifolds to describe the $\mathrm{CH}_{4} /$ coal strained stagnation flames is evaluated by means of a budget analysis [25]. Assuming that any scalar quantity $\Psi=\Psi^{\mathrm{tab}}\left(\phi_{i}\right)$ (i.e., $\left.T, Y_{i}\right)$ is a function of the table control variables $\phi_{i}$ $\left(Z_{v}, Z_{p}, Y_{C}\right.$, and $\left.h_{g}\right)$, the first and second derivatives in the transport equations formulated in physical space $x$ can be rewritten using the chain rule:

$$
\begin{aligned}
& \frac{\partial \Psi}{\partial x}=\sum_{i=1}^{N_{p}} \frac{\partial \Psi}{\partial \phi_{i}} \frac{\partial \phi_{i}}{\partial x} \\
& \frac{\partial^{2} \Psi}{\partial x^{2}}=\sum_{i=1}^{N_{p}} \sum_{j=1}^{N_{p}} \frac{\partial^{2} \Psi}{\partial \phi_{i} \partial \phi_{j}} \frac{\partial \phi_{i}}{\partial x} \frac{\partial \phi_{j}}{\partial x}+\sum_{i=1}^{N_{p}} \frac{\partial \Psi}{\partial \phi_{i}} \frac{\partial^{2} \phi_{i}}{\partial x^{2}} .
\end{aligned}
$$

Thus, the transport equation of the scalar $\Psi$ in the FTC model (Eqs. (3) and (4)) can be expressed as a function of the table control variables $\phi_{i}$, substituting the derivatives with Eqs. (15) and (16). In the budget analysis of the transport equation, the derivatives in physical space $\left(\partial \phi_{i} / \partial x\right.$ and $\left.\partial^{2} \phi_{i} / \partial x^{2}\right)$ 


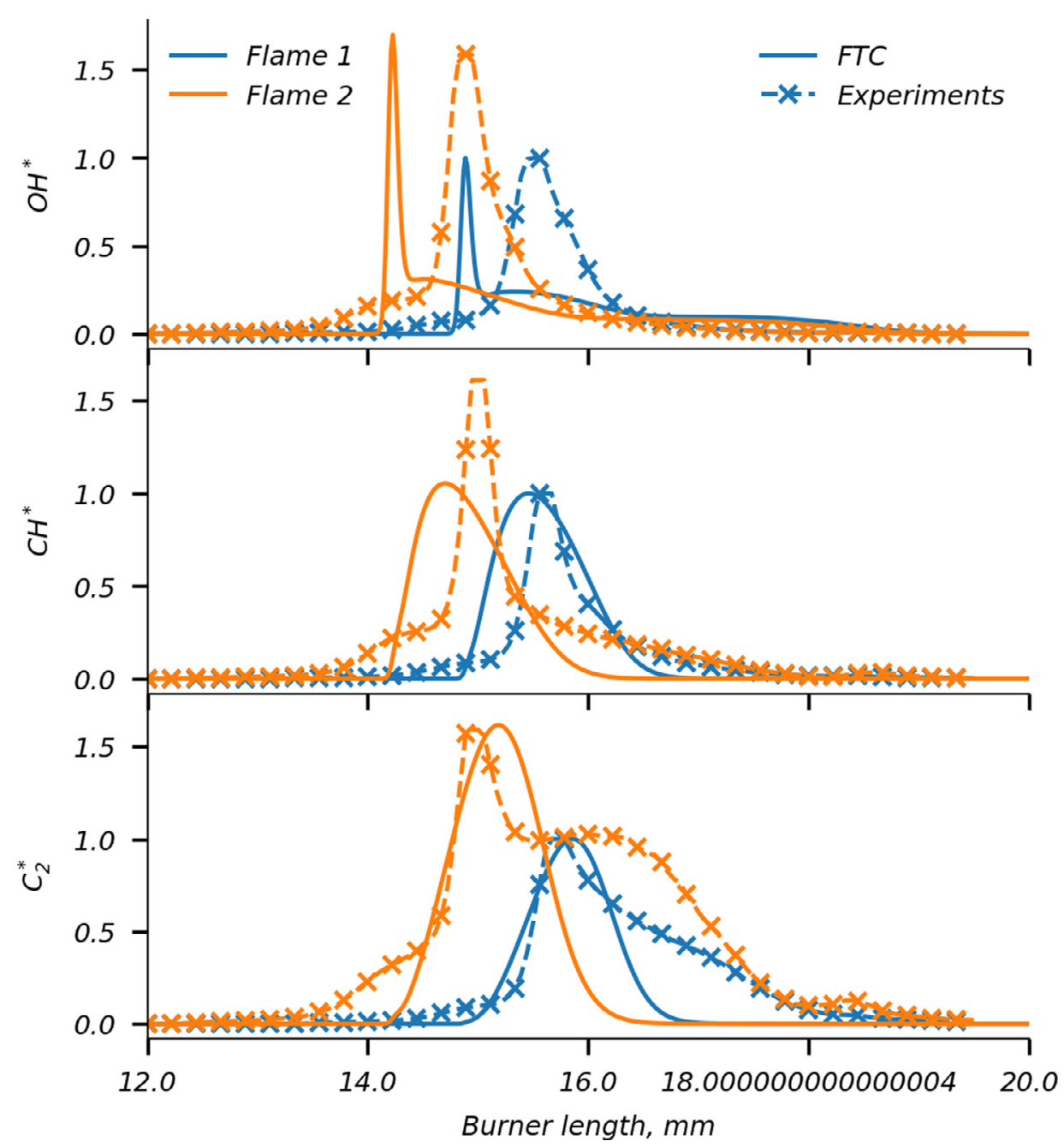

Fig. 2. Comparison of the FTC model to experiments for the normalized mole fractions of $\mathrm{OH}, \mathrm{CH}^{*}$ and $\mathrm{C}_{2}^{*}$. The symbols show the experiments and the solid lines the FTC results. Both experiments and numerical results are scaled by the corresponding maximum values of each species for Flame 1.

are directly taken from the reference FTC solution, while the derivatives in control variable space $\left(\partial \Psi / \partial \phi_{i}\right.$ and $\left.\partial^{2} \Psi / \partial \phi_{i} \partial \phi_{j}\right)$ are calculated from the tabulated solution. Finally, if the budget analysis of the transport equation rewritten as a function of the control variables is closed, the manifold used to build the table correctly describes the main features of the flame. Additionally, by analyzing the individual term of the budget, it is possible to evaluate the influence of the different control variables and their interactions with the others.

\section{Numerical setup}

The simulations are performed with the inhouse 1D Universal Laminar Flame (ULF) code [26]. The homogeneous reactions are modeled by USC-Mech II kinetic mechanism [27], extended with a sub-mechanism for $\mathrm{CH}^{*}$ [28]. Coal devolatilization is modeled using the Single First Order Reaction (SFOR) model [29]. The kinetic parameters are calibrated using results of the CPD model [30] for reference. A previous work of the authors [31] demonstrated that empirical models can accurately describe coal devolatilization when their parameters are calibrated using detailed models, as CPD. The calibrated pre-exponential factor and activation energy are $A_{v}=236012.051 / \mathrm{s}$, $E_{v}=47.083 \mathrm{~kJ} / \mathrm{mol}$, while the final volatile yield is $y_{0}=0.671$. Char oxidation is modeled using the external surface model developed by Baum and Street [32], whose parameters are taken from [17].

The look-up table used for the FPV simulations is built assembling $21 \times 31 \times 5$ premixed 1 D flamelets, with $Z$ defined between 0 and $0.2, Y$ between 0.6 and 1 , and the ratio between the burner 


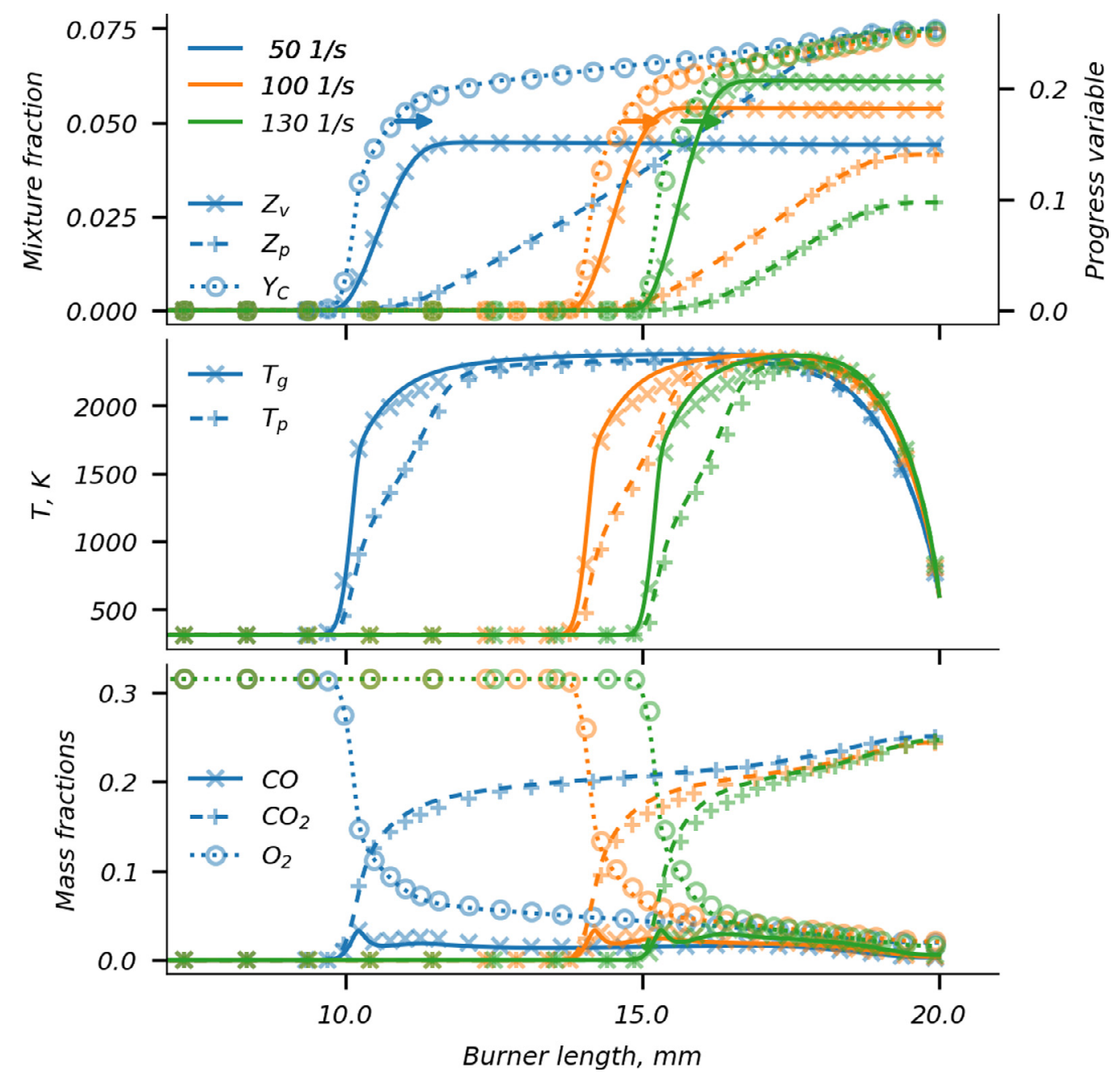

Fig. 3. A posteriori analysis of the stagnation flames at different strain rates (represented by different colors). The FTC and FPV results are shown by lines and symbols, respectively.

inlet velocity and the laminar flame speed between 0.2 and 1. Each premixed flamelet is converted from the physical reactor length into the progress variable space $C$. The progress variable is defined as the sum of the mass fraction of $\mathrm{CO}$ and $\mathrm{CO}_{2}$ [15]. The assembled 1D flamelet solutions finally result in a 4 dimensional table, including the three external parameters $(Z, Y$ and the inlet velocity) and the internal parameter $C$.

The composition of the inlet gas is defined by $\Phi$ and the oxygen content in the oxidizer. The composition of the volatile products is defined as a mixture containing light gases and tar, approximated as $\mathrm{C}_{6} \mathrm{H}_{6}[15,33]$. The assumed mass fractions of the volatiles are: $\mathrm{C}_{6} \mathrm{H}_{6} 42.32 \%, \mathrm{H}_{2} 4.21 \%$, $\mathrm{CO} 6.48 \%$, $\mathrm{CO}_{2} 45.8 \%$, and $\mathrm{N}_{2} 1.2 \%$. The composition of the char burnout products is defined by Eq. (11).

\section{Results}

\subsection{Validation of numerical models}

The FTC approach is validated using the experimental chemiluminescence signals of $\mathrm{OH}^{*}$, $\mathrm{CH}^{*}$ and $\mathrm{C}_{2}^{*}$ for Flames 1 and 2. Figure 2 shows the comparison between the experiments and numerical results. The measured intensities of the chemiluminescent species are normalized with the corresponding maximum value for each species in Flame 1. The same normalization is done for the numerical results, using the maximum values in Flame 1. Flame 2 is characterized by a higher $\Phi$, which shifts the flame position to the left side compared to Flame 1. The higher content of $\mathrm{O}_{2}$ in Flame 1 only partially mitigates this effect. Flame 2 is also characterized by more intense 


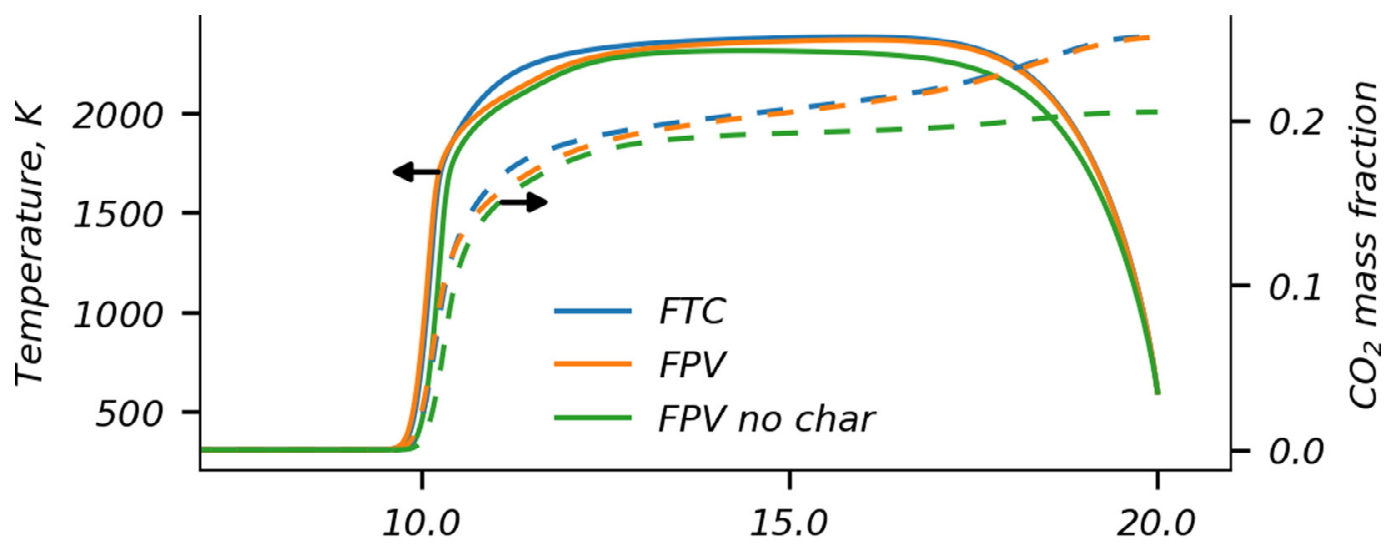

Burner length, $\mathrm{mm}$

Fig. 4. Comparison between the temperature and $\mathrm{CO}_{2}$ predicted by the FTC, FPV and FPV without char conversion for $k=501 / \mathrm{s}$.

chemiluminescence signals, which are generally $50 \%$ higher than in Flame 1. The comparison between the numerical results and the experiments shows a generally satisfactory agreement, demonstrating that the numerical results are able to correctly predict the flame position. The results obtained are similar to the ones obtained by Xia et al. [17] with the EM2C in house REGATH code. The deviations from the experiments are large if compared to standard gas flames, however they are comparable to other numerical works investigating coal combustion $[3,9,12]$. For both flames, the numerical peaks of $\mathrm{OH}^{*}$ are shifted leftwards with respect to the experiments. Similar trends for the comparison of the experiments and the numerical simulations were observed by Xia et al. [17]. The maximum value of the numerical $\mathrm{OH}^{*}$ scales similarly to the experiments from Flames 1 to 2. The positions of the $\mathrm{CH}^{*}$ and $\mathrm{C}_{2}^{*}$ peaks are also correctly predicted for both flames.

\subsection{A posteriori analysis}

Flames 1 and 2 only show a limited char burnout. In Flame 1, which has the highest char conversion, the maximum value of the $Z_{p}$ is 0.029 , which is nearly the half of the maximum value of $Z_{v}=0.06$. This value corresponds to an overall char conversion of $24.6 \%$. Since the main goal of this work is to investigate the influence of the char products in the multistream FPV model, different operating conditions are analyzed aiming at maximizing the overall conversion of char, which might be very challenging to achieve experimentally in this configuration, and studying the interaction between $Z_{v}$ and $Z_{p}$. Thus, the inlet velocity and consequently the strain rate $\left(k=v_{\text {in }} / L\right)$ are reduced with the goal of increasing the particles residence time and maximizing the overall char conver- sion. The strain rate of flame 1 (1301/s) is reduced to $1001 / \mathrm{s}$ and $501 / \mathrm{s}$. In fact, for a strain rate of 501/s, $Z_{p}$ increases up to 0.075 , which corresponds to an overall char conversion of $76.9 \%$.

For each strain rate, the results of the fully coupled FPV model are compared against the reference FTC solutions. The comparison between FTC and FPV results, generally defined as a posteriori analysis [15], is reported in Fig. 3. At first, $Z_{v}, Z_{p}$ and $Y_{C}$ are compared. These quantities are control variables of the FPV model, and they are directly obtained by the solutions of Eqs. (12) and (13). In the FTC model, these transport equations are solved with the only purpose of validating the FTC results. The comparison shows a good agreement between the FPV and the reference FTC simulations.

The second subplot shows the gas and particle temperatures. The flame location is generally is well predicted by the FPV model, but there are small deviations downstream in the post-flame zones. Since the table control parameters $\left(Z_{v}, Z_{p}\right.$ and $\left.Y_{C}\right)$ are generally correctly predicted by the FPV approach, the temperature deviations mainly depend on the premix manifold used. Similar behaviors are observed in the last subplot for the main chemical species. In general, $\mathrm{O}_{2}$ is accurately predicted, while $\mathrm{CO}$ and $\mathrm{CO}_{2}$ are over- and underestimated by the FPV model.

In order to quantify the influence of the mixture fraction of char products, the results of the FPV model with only the volatile mixture fraction are reported in Fig. 4 for the flame with $k=$ 501/s. The predicted temperature and $\mathrm{CO}_{2}$ mass fractions are compared with the results of the reference FTC solution and with the FPV solution accounting for the char conversion. The comparison shows that both the temperature and the $\mathrm{CO}_{2}$ are under predicted when the char products are not in- 


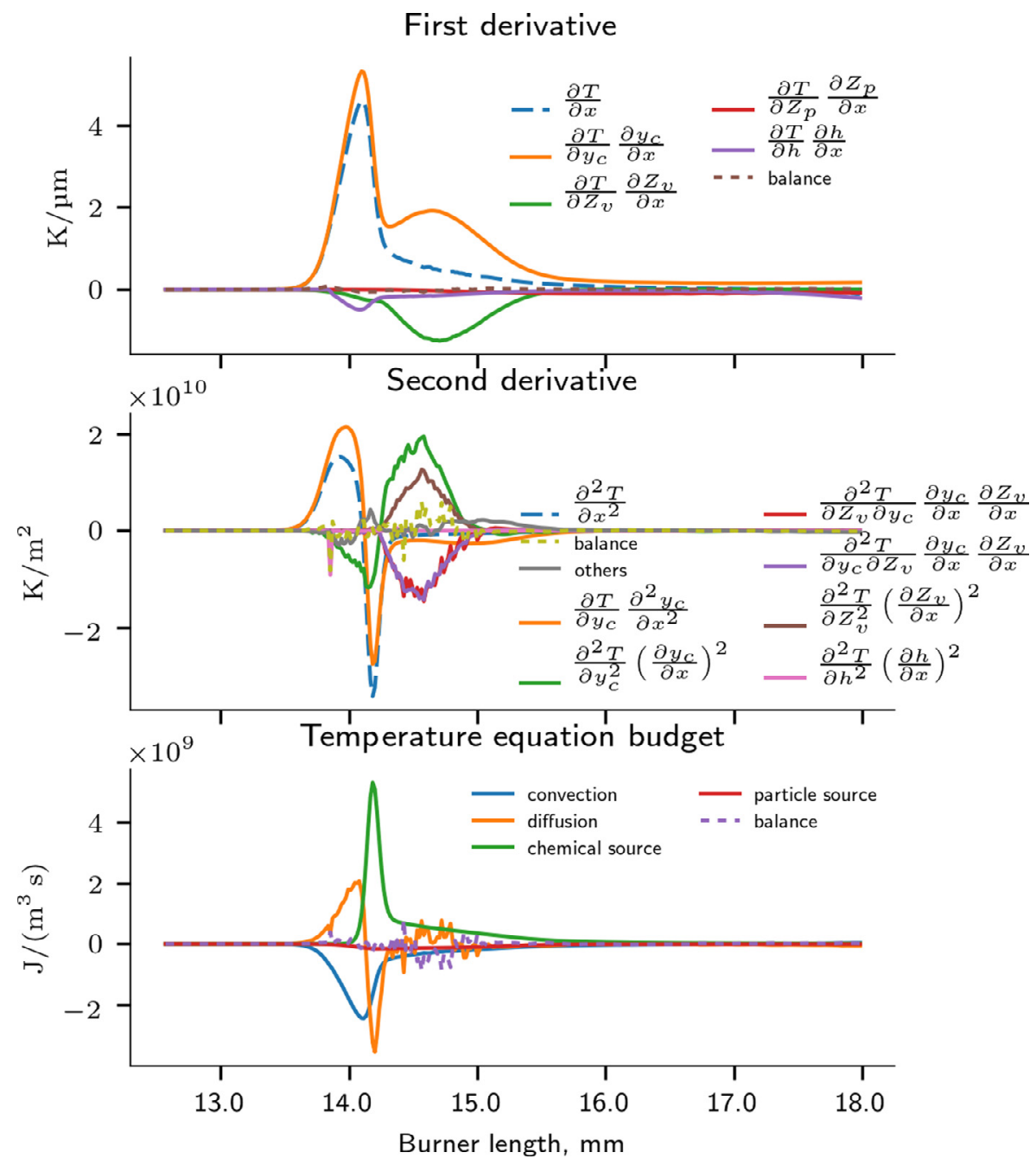

Fig. 5. Budget analysis of the temperature transport equation (Eq. (3)) for $k=1001 / \mathrm{s}$. The first plot and second plots show the first and second derivative budgets, respectively. The lower plot shows the overall budget of the temperature transport equation.

cluded in the table. In particular, an absolute deviation of 0.04 is observed for $\mathrm{CO}_{2}$ at the stagnation point. The comparison shows that the char products have an important contribution in the final results, and they cannot be neglected in the look-up table.

\subsection{Budget analysis}

In the budget analysis, the contribution of each individual control parameter of the tabulated solution is directly assessed on the transport equations of the reference FTC model. Figure 5 shows the budget analysis of the temperature transport equation (Eq. (3)) for a strain rate of 100 1/s. In order to have a better understanding of the influence of the individual control variables, the budgets of the first and second derivatives are reported separately in the first two subplots. For the first derivative $\partial T / \partial x$, the balance is well closed using the tabulated manifold, and only minor deviations are present. At the flame front $(x=14 \mathrm{~mm})$, the term conditioned to $Y_{C}$ is the most important contribution to the temperature gradient. In fact, this region is governed by the combustion of $\mathrm{CH}_{4}$, which leads to an increase of $Y_{C}$. The enthalpy $h$ is also contributing to a lesser extent, which accounts for the heat transfer with the coal particles. As soon as the devolatilization takes place (14.2 $\mathrm{mm}$ to $15.3 \mathrm{~mm}$ ), the term with respect to $Z_{v}$ becomes important. Contrary, the term with respect to $Z_{p}$ only contributes to the overall temperature gradient slightly in the postflame zone, because of the slow char burnout rate. 
The influence of $Z_{p}$ is more evident in budgets of the $\mathrm{CO}_{2}$ (not shown here). In the analysis of the second derivative $\partial^{2} T / \partial x^{2}$, only the major contributions are shown in the figure. The budget of the second derivative shows a relative error of about $24 \%$ in the devolatilization zone, where the terms with respect to $Z_{v}$ become relevant. This error can be related directly to the manifold used. In fact, the premixed flamelets, combined to build the tabulated manifold, do not include any interactions in the directions of the mixture fractions. These interactions are simply modeled, assuming that the assembled premixed flamelets can reproduce the complex interactions between the control variables existing in more complex flames.

The last plot shows the overall budget of the temperature transport equation reporting the main terms. In the devolatilization region, an average balance error of about $12 \%$ is observed, which mainly originates from the error already observed in the second derivative. This error can be directly linked to the deviations seen in the a posteriori analysis in Fig. 3. Hence, the deviations between FPV and FTC model, mainly occurring during devolatilization, are directly linked to the manifold in the lookup table, based on premixed flamelets, which cannot accurately account for large gradients of $Z_{v}$. Nevertheless, the overall agreement between FPV and FTC model is remarkable, noting that contributions from derivatives with respect the control variables $Z_{v}, Z_{p}$ and $h$ originate uniquely from the assembly of flamelet solutions with different fuel mixtures and enthalpy levels.

\section{Conclusions}

A multi-stream Flamelet Progress Variable (FPV) model is investigated in a $\mathrm{CH}_{4} / \mathrm{coal}$ strained stagnation flame configuration. The FPV model is based on a look-up table which is constructed from premixed flamelets and parameterized by four control variables: the volatile and char burnout mixture fractions, the progress variable and the enthalpy. The FPV model is first compared to an experimentally validated Full Transport and Chemistry (FTC) solution (a posteriori analysis). The results of the FPV model show good agreement with the reference solution in terms of temperature and major species profiles. Only minor differences are observed in the flame and post-flame zone. The influence of the control variables in the look-up table is then examined by means of a budget analysis, by evaluating the conditional contributions of the control variables to the overall transport equation. The analysis shows that during the combustion of $\mathrm{CH}_{4}$ at the front of the flame, the budget, dominated by the progress variable derivatives, is correctly closed. On the contrary, the combustion of the volatile products, dominated by the mixture fractions derivatives, shows a budget er- ror of about $12 \%$. This error is directly related to the manifold used, since the premixed flamelets do not include any interactions in the directions of the mixture fractions. Hence, the budget errors are observed where mixture fraction gradients show significant influence, which is directly linked to the deviations in the a posteriori analysis.

This study shows that multi-stream FPV modeling approaches provide reliable results even though the flamelets used to build the look-up table neglect certain relevant characteristics of the flame structure. In the context of the results of a previous study [15], which used a tabulated manifold constructed from non-premixed flamelets, it still remains a subject for further research how to accurately model multiple burning modes occurring in complex PCC flames. With this in mind, hybrid tabulation strategies might allow to account for the different local flame regimes existing in complex PCC burners.

\section{Acknowledgments}

The authors acknowledge the financial support by the German Research Foundation (DFG) for the collaborative project Multi-Dimensional Flamelet Modeling for LES of Pulverized Coal Flames (project number HA 4367/3-1) and the Federal Ministry of Economic Affairs and Energy (BMWi) of Germany for the project HotVeGas III (project number 0327773J).

\section{References}

[1] R. Kurose, H. Makino, Combust. Flame 135 (2003) $1-16$.

[2] P. Edge, S. Gubba, L. Ma, R. Porter, M. Pourkashanian, A. Williams, Proc. Combust. Inst. 33 (2011) 2709-2716.

[3] O.T. Stein, G. Olenik, A. Kronenburg, et al., Flow Turbul. Combust. 90 (2013) 859-884.

[4] B. Franchetti, F.C. Marincola, S. Navarro-Martinez, A. Kempf, Proc. Combust. Inst. 34 (2013) 2419-2426.

[5] G. Olenik, O. Stein, A. Kronenburg, Proc. Combust. Inst. 35 (2015) 2819-2828

[6] M. Rabacal, B. Franchetti, F.C. Marincola, et al., Proc. Combust. Inst. 35 (2015) 3609-3617.

[7] B. Franchetti, F.C. Marincola, S. Navarro-Martinez, A. Kempf, Fuel 181 (2016) 491-502.

[8] B. Fiorina, D. Veynante, S. Candel, Flow Turbul. Combust. 94 (2015) 3-42.

[9] M. Rieth, A.G. Clements, M. Rabacal, F. Proch, O.T. Stein, A.M. Kempf, Proc. Combust. Inst. (2017) 2181-2189. 
[10] M. Rieth, F. Proch, M. Rabacal, B. Franchetti, F.C. Marincola, A. Kempf, Combust. Flame (2016).

[11] J. Watanabe, K. Yamamoto, Proc. Combust. Inst. 35 (2015) 2315-2322.

[12] J. Watanabe, T. Okazaki, K. Yamamoto, K. Kuramashi, A. Baba, Proc. Combust. Inst. 36 (2017) 2155-2163.

[13] R. Knappstein, G. Kuenne, A. Ketelheun, et al., Combust. Flame 169 (2016) 72-84.

[14] X. Wen, Y. Luo, K. Luo, H. Jin, J. Fan, Fuel 188 (2017) 661-671.

[15] D. Messig, M. Vascellari, C. Hasse, Combust. Theor. Model. 21 (2017) 700-721

[16] C. Pierce, P. Moin, J. Fluid Mech. 504 (2004) 73-97.

[17] M. Xia, D. Zabrodiec, P. Scouflaire, B. Fiorina, N. Darabiha, Proc. Combust. Inst. 36 (2017) 2123-2130

[18] R.J. Kee, J.A. Miller, G.H. Evans, G. Dixon-Lewis, Symp. (Int.) Combust. 22 (1989) 1479-1494.

[19] C. Hasse, N. Peters, Proc. Combust. Inst. 30 (2005) 2755-2762.

[20] M. Vascellari, H. Xu, S. Hartl, F. Hunger, C. Hasse, Chem. Eng. Sci. 134 (2015) 694-707.

[21] S. Popp, F. Hunger, S. Hartl, et al., Combust. Flame 162 (2015) 3016-3029.

[22] O. Gicquel, N. Darabiha, D. Thvenin, Proc. Combust. Inst. 28 (2000) 1901-1908.
[23] J.V. Oijen, L.D. Goey, Combust. Sci. Technol. 161 (2000) 113-137.

[24] B. Fiorina, R. Baron, O. Gicquel, D. Thevenin, S. Carpentier, N. Darabiha, Combust. Theor. Model. 7 (2003) 449-470.

[25] P.D. Nguyen, L. Vervisch, V. Subramanian, P. Domingo, Combust. Flame 157 (2010) 43-61.

[26] A. Zschutschke, D. Messig, A. Scholtissek, C. Hasse, Universal Laminar Flame Solver (ULF), 2017. 10. 6084/m9.figshare.5119855.v2

[27] H. Wang, X. You, A. Joshi, et al., USC Mech Version II. High-Temperature Combustion Reaction Model of $\mathrm{H}_{2} / \mathrm{CO} / \mathrm{C}_{1}-\mathrm{C}_{4}$ compounds, 2007. http://ignis.usc. edu/USC_Mech_II.htm. Accessed 18 Jun. 2018

[28] D. Alviso, J.C. Rolon, P. Scouflaire, N. Darabiha, Fuel 153 (2015) 154-165.

[29] S. Badzioch, P.G.W. Hawksley, Ind. Eng. Chem. Proc. Des. Dev. 9 (1970) 521-530.

[30] D.M. Grant, R.J. Pugmire, T.H. Fletcher, A.R. Kerstein, Energy Fuel 3 (1989) 175-186.

[31] M. Vascellari, R. Arora, M. Pollack, C. Hasse, Fuel 113 (2013) 654-669.

[32] M.M. Baum, P.J. Street, Combust. Sci. Technol. 3 (1971) 231-243

[33] G.L. Tufano, O.T. Stein, A. Kronenburg, et al., Fuel 186 (2016) 285-292. 